\title{
SINO-AURICULAR BLOCK DUE TO TOBACCO POISONING*
}

\author{
SELIAN NEUHOF, M.D. \\ NEW YORK
}

Sino-auricular block-standstill of the entire heart-is a rare type of arhythmia in the adult. It is usually the result of digitalis poisoning. ${ }^{1}$ Recently, however, a case due to salicylic acid has been described. $^{2}$ It has occasionally been induced by vagal pressure $^{3}$ in patients with normal rhythm and with paroxysmal tachycardia ${ }^{4}$ and has frequently been induced experimentally. ${ }^{5}$ The report of its occurrence as a clinical condition with accompanying graphic proof is exceedingly rare. ${ }^{5,6}$.

It has long been known that overindulgence in tobacco causes arhythmias, but their type has not been sufficiency studied by graphic methods to determine their exact nature. I have observed several cases of extrasystoles (usually auricular), one case of auricular flutter and one of auricular fibrillation due to tobacco poisoning. As sinoauricular block has never been ascribed to this cause, the following two cases seem sufficiently noteworthy to warrant publication.

CASE 1.-E. I. H., aged 28, architect, married six years, has two children. He was always athletic. When 6 years old he had diphtheria with tracheotomy; otherwise he has had no serious illness. At 15 he began smoking and has been smoking uninterruptedly since, his usual quota being three cigars and three pipefuls daily; never cigarets. His pulse irregularity was first noticed when examined for admission to the army at the age of 20 . His arhythmia does not annoy him or in any wise interfere with his work or exercise. There was no dyspnea on exertion and the arhythmia was not affected by exercise. There was no precordial pain or decompensation. The systolic blood pressure was $150 \mathrm{~mm}$., the diastolic, $70 \mathrm{~mm}$. There was a vigorous apical impulse and the cardiac sounds were normal. Orthodiascopic examination showed slight left ventricular enlargement. The urine showed no abnormalities, and examination of the abdominal organs and the nervous system revealed nothing of note. The heart contracted regularly at the rate of about 100 per minute for two, three, or four beats and then there was a sudden pause during which no sound was heard at the apex nor any pulse beat felt at the wrist. Examination of the

* Submitted for publication, Jan. 3, 1916.

1. Hewlett: Jour. Am. Med. Assn., 1907, 1vii, 47. Rih1: Deutsch. Arch. f. klin. Med., 1908, xciv, 286. Cohn and Fraser: Seventeenth International Congress of Medicine, 1913, Section 6, Medicine.

2. Sicard and Meara: Am. Jour. Med. Sc., 1915, cl, 843.

3. Robinson and Draper: Jour. Exper. Med., 1911, xiv, 217. Von Hoesselin: Deutsch. Arch. f. klin. Med., 1914, cxiii, 537.

4. Cohn and Fraser: Heart, 1913-14, v, 93.

5. Eyster and Evans: The Archives Int. Med., 1915, xvi, 832.

6. Lewis: Clinical Electrocardiography, p. 100. 


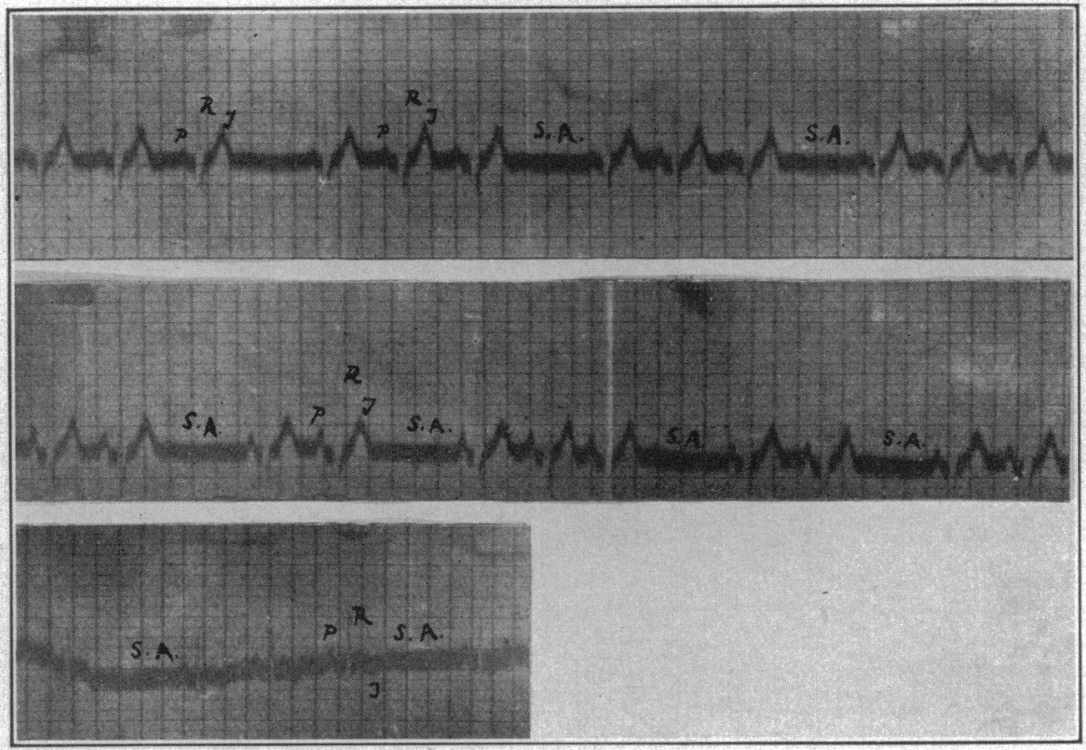

Figure 1

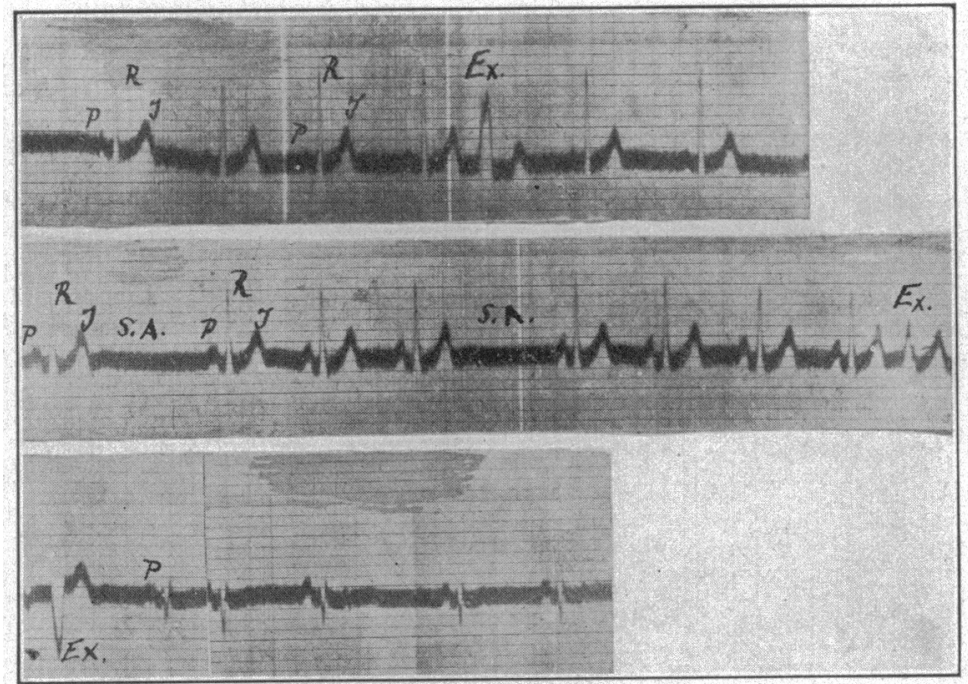

Figure 2

Figure 1.--Electrocardiogram from Case 1. In this figure and Figure 2 the vertical lines measure one-fifth second; the different leads are marked 1, 2, 3; $\mathrm{P}=$ the auricular, R-T, the ventricular complex. S.A. = sino-auricular block, $\mathrm{Ex}=$ ventricular extrasystole. 
electrocardiogram (Fig. 1) showed sino-auricular block, a sudden arrest of the whole heart (S. A., Fig. 1). The length of most of the pauses was somewhat less than two normal beats, a condition ordinarily found in this type of arhythmia. The patient refused to stop smoking; the arhythmia continued. This case was uncomplicated by any evidence of organic cardiovascular disease.

CASE 2.-A. B., physician, aged 57; always led a very active life; had been a heavy and constant cigaret smoker since youth, averaging thirty cigarets daily. Several years ago he was treated medically for duodenal ulcer and has had no symptoms since. During the last eight years he has complained of some dyspnea. In addition, for the last two or three years he has had occasional attacks of precordial pain. For several months both symptoms have become worse. His pulse irregularity began eight months ago. The patient was somewhat stout; his color pasty gray. The average systolic blood pressure was $150 \mathrm{~mm}$; t the diastolic, $100 \mathrm{~mm}$. There was no pain on precordial pressure. Except for a faint systolic murmur at the right base, the heart sounds were normal. The orthodiascope showed that the aortic arch and left ventricle were somewhat enlarged. The neurological status was normal. There was slight edema of the legs. On one examination the urine contained a few hyaline casts and a slight trace of albumin. Extrasystoles were heard at the apex and transmitted to the wrist about once in every three or four beats; their number decreased after exercise. Besides the extrasystoles, there were occasional complete pauses of the heart and pulse; the electrocardiogram (Fig. 2, lead 2, S. A.) showed that the pauses were due to sino-auricular block and almost equalled two normal contractions. Ventricular extrasystoles (Fig. 2) were seen in the different leads. The ventricular rate, when rhythmical, was about 80 per minute; the conduction time (P-R interval), normal. The patient was advised to stop smoking and moderate doses of bromids were prescribed. The sino-auricular block disappeared within three days and has not since returned. The extrasystoles also disappeared for a few days, but then recurred about once every minute; after two weeks they were as frequent as at the first examination. With their return, precordial pains and dyspnea increased. Digipuratum tablets, three daily, and theobromin sodium salicylate, with Karrel diet, once weekly, were prescribed, and the patient's work was somewhat restricted. Within three weeks, the extrasystoles, precordial distress and dyspnea entirely disappeared. Except for occasional ventricular extrasystoles following extreme effort, the patient feels quite comfortable.

A study of the history and clinical course showed that the two distinict types of arhythmia, sino-auricular block and ventricular extrasystoles, were apparently caused by two different factors, the former by tobacco, the latter probably by myocarditis and nephritis. The sino-auricular block disappeared very soon after smoking was stopped; the extrasystoles, only when compensation was fully restored. Ventricular extrasystoles are known to accompany any type of cardiovascular disease with decompensation. With restoration of compensation they usually disappear, a result that was accomplished in this case.

\section{COMMENT}

Sino-auricular block is commonly ascribed to a vagus influence acting on the sinus region of the heart in which lies the pacemaker (the sino-auricular node) with its rich nerve plexuses and ganglia; morbid vagus influences may block out an entire sequential auriculo- 
ventricular contraction and produce a corresponding pause of cardiac activity. In animals the experimental effects on the heart and aorta of nicotin injections and of tobacco inhalations and their possible correlation with similar cardiovascular disease in man are still disputed questions and have no bearing on the subject matter of this paper. These observations, however, have tended to minimize the definitely known poisonous effects of nicotin on nerves and nerve endings. Langley and Sherrington ${ }^{7}$ were among the first to demonstrate the neurotropic effects of nicotin, the most active of the tobacco alkaloids. Pezzi and $\mathrm{Clerc}^{8}$ studied the effects of nicotin injections upon cardiac rhythm and divided these into an initial bradycardial, and a later tachycardial, phase. In the former, they occasionally noted auricular arrest with ventricular arhythmia, and less frequently auricular fibrillation; with the tachycardia, they observed lessened auriculoventricular conduction time, retrograde conduction, auricular extrasystoles or incomplete auriculoventricular dissociation. Cushny ${ }^{9}$ showed that experimental nicotin injections disturbed normal cardiac rhythm mainly by a morbid neurotropic influence acting on the ganglionic terminations of the vagus and sympathetic nerves; thus it seemed possible to have two opposite effects on heart rate-abnormal slowing or acceleration-apparently depending on the preponderant selective action for vagus or accelerator nerve endings. That such action may rapidly shift from one to the other seems plausible from our present scanty clinical knowledge that nerve tone may be a very unstable quality, at times readily influenced.

The clinical cases here reported seem to substantiate, in a degree, the results of animal experimentation. In Case 2, the extrasystoles were the result of decompensation. The sino-auricular block represented the effects of nicotin poisoning on the vagus alone. Patient 1 had no organic disease. The moderate acceleration interspersed with irregularly occurring sino-auricular block was apparently a clinical prototype of the two opposed experimental effects of the tobacco alkaloid on the vagus and accelerator.

1275 Madison Avenue.

7. Langley and Sherrington: Jour. Physiol, 1891, xii, 43.

8. Pezzi and Clerc: Jour. de physiol. et path. gén., 1913, xv, 1.

9. Cushny: Pharmacology and Therapeutics of the Action of Drugs, 1913, p. 272 . 